three species of wild deer on Rum in the Inner Hebrides. This paper was notable for some very beautiful illustrations of the habitats. The rigour of a littorine habitat was apparent in the discussion by B. L. James (Aberystwyth) of the development and life-history of Parvatrema homoeotecnum n.sp., a gymnophalline trematode which parasitizes the gastropod molluse, Littorina saxatilis and oyster eatchers. This parasite shows several specialized and primitive features. The perch and pike in Llyn Tejid in Merionethshire are the hosts of a pseudophyllidean cestode, Triaenophorus nodulosus. By taking regular nettings, J. C. Chubb (Liverpool) was able to obtain data relating the incidence and development of the parasite to the growth of the fish. Also following this theme of seasonal incidence, but with quite a different parasite, W. N. Beesley (Weybridge) discussed the development and migration of Hypoderma bovis and $H$. lineatum in domestic cattle.

Work during recent years has shown that parasitology is a fertile field for the application of new laboratory techniques. Thus, cytochemical techniques were used to characterize the functions of the male accessory and reproductive glands of Argas persicus (R. J. Tatchell, Cambridge), and the pseudosuckers and holdfast organ of the trematode Diplostomum phoxini (D. L. Lee, Cambridge). The nutritional requirements of the latter have been the subject of in vitro cultural studies by C. A. Hopkins and M. O. Williams (Glasgow). In the field of immunology, agar diffusion techniques have been applied to such widely differing subjects as Eimeria infections in fowls (M. E. Rose and P. L. Long, Houghton) and schistosomes in monkeys (S. R. Smithers, National Institute for Medical Research). Despite the application of new techniques, parasitology still occasionally requires systematic descriptions, an example of which was the paper by S. T. Fernando (Cambridge) dealing with the developmental stages of Mecistocirrus digitatus, a nematode found in the abomasum of cattle in Ceylon, India and the Far East.

The proceedings of this meeting will not be published in detail. The spring meeting in 1962 is to be held in Cambridge during April 3-5.

L. P. JOYNER

\title{
WATER RESOURCES IN WALES
}

$\mathrm{L}^{\mathrm{s}}$ ARGELY as a result of the water supply difficulties of 1955 and 1957 , the Minister of Housing and Local Government (who is also Minister for Welsh Affairs) appointed in February 1958 a committee to advise him on the use and conservation of water resources in Wales. The Committee has already expressed interim views in February 1959 on the Milford Haven barrage scheme (which it favoured), and has recently published its first full Report on the Water Resources of Wales*.

This report is a notable advance forward in our knowledge of the Water Resources of Great Britain and in their proper employment. The Minister indicated to the Committee that the most urgent problem was to assess the water resources in relation to foreseeable demand, and three guiding questions were posed: (a) What are the water resources? (b) What is the exploitable surplus ? and (c) How can such surplus best be employed?

The Committee consisted of persons from different parts of Wales with interests in hydrology but not themselves engineers or technical experts. The report, as a result, considers not only the hydrological survey of Wales carried out by the Ministry's engineers in 1957 but also social, economic and cultural aspects of the problems encountered. The hydrological survey (not generally available) gives detailed estimates of the maximum supply of water which could be obtained from Wales on the assumption that hydrological considerations are the sole governing factor. The Committee, however, examined more than 180 suggested reservoir sites in the light of $(a)$ geological structure, $(b)$ agricultural interests, (c) existing communities, (d) amenities, and (e) cost. The sites were then placed in one of four categories: ' $A$ ' sites, to which no objection could be seen; ' $B$ ' sites, where a moderate degree of objection was foreseen; ' $C$ ' sites, development of which could only be envisaged if the need for water in the country as *Welsh Advisory Water Committee. Report on the Water Resources
(London: H.M.S.O., 1961.) 58. net. a whole were to become over-riding; and lastly, sites rejected as completely unsuitable.

As the Committee also considered the various resources in relationship to conventional impounding reservoirs, regulating reservoirs, estuarine reservoirs and direct abstraction, it will be immediately apparent that there is no clear-cut and definite answer to the first question: "What are the water resources of Wales ?". Appendix 8 of the report, however, sets out the various possibilities : these, on the Committee's definition, range from a minimum of 1,195 million gallons a day to a maximum of 2,895 million gallons a day.

These resources are next considered in relationship to the demand for water. Here the Committee has not only considered the present situation but also has looked ahead into the 'foreseeable future'. This has been taken, despite the hazards of extrapolation, as a period of 30 years. For this purpose Wales is divided into five geographical zones-south-west, north-west, north-east, south-east and central. In only one of these zones, the south-east, has the Committee found serious prospective deficiency of water : in all the others there is not only an adequate amount of available water but also an exploitable surplus. Ample allowance has been made in these calculations for a continued expansion in the Welsh economy and for increased demands for water. The Committee estimates that, taken as a whole, the Principality has an exploitable surplus of resources over demand of between 235 and 800 million gallons a day according to the system of development adopted (this is seen in perspective when it is recollected that public undertakings in England and Wales at present supply some 2,400 million gallons a day).

The Committee suggests that that part of the surplus which can be most easily used to supply areas in England which are short of water is to be found in the upper basins of the Severn, Wye and Dee (the 'central zone'). 'This is an area of heavy rainfall and very low population with limited local demands on 
the water resources. The report stresses that this should be achieved by means of regulating reservoirs such as that proposed in the Tryweryn scheme. This type of reservoir regulates the flow of water down the river, and water is then abstracted from the lower reaches: there is no pipe-line as with the impounding reservoir.

The Committee raises an important point in the suggestion that rural areas where large reservoirs have been sited have not always received adequate economic returns. They believe a case exists for a system whereby material benefit should be received by such areas in addition to the extra revenue available in the form of rate income. Adequate compensation for displaced residents and disrupted farmeconomies would also ease the transition from traditional types of land use to water storage. A realistic approach on these lines would help to create a better understanding between the city and town dwellers and the inhabitants of the rural catchment areas.

The report is full of valuable statistical data, and provides for the first time an indication, in the light of economic, social and cultural considerations, of the hydrological situation within the Principality in relationship to present and future needs of water supply. A clear and concise geographical account is also given of each of the five zones demarcated (although the authors of the report have somewhat oddly listed the physical geography as 'geography'; actually the whole of each of the respective chapters falls within the scope of a geographical consideration). As a work of reference and as a guide for future policy decisions the report will be invaluable.

Water in Wales may also raise from time to time 'political' problems regarding the 'export' to England. This aspect is also considered by the Committee. It believes that, in a period when water will become relatively more scarce, Wales will have many advan. tages for water-seeking firms and for agricultural irrigation. While noting that public opinion in Wales would not take kindly to the idea of a wholesale export of water without reference to long-term needs within Wales, the Committee is able to conclude that Wales has such an abundant rainfall that there is, and will continue to be, a large exploitable and 'exportable' surplus of water if the resources were properly developed by the construction of suitably sited regulating reservoirs. W. G. V. BALCHIN

\title{
CHEMICAL COMPOSITION OF PRECIPITABLE WATER VAPOUR OVER THE UNITED STATES
}

\author{
By Drs. HENRY M. PAPÉE and ALBERTO MONTEFINALE
}

Centre for Aerosol Nucleation, National Research Council of Italy, Via Vettore 4 (Monte Sacro), Rome

$\mathrm{D}^{\mathrm{A}}$ ATA on annual average amounts of precipitable water vapour in the atmosphere over several stations of the United States and up to $525 \mathrm{~m}$.b. have recently been published by Reitan ${ }^{1}$, and it appeared to be of interest to us to attempt a correlation between these data, Junge's rain-water content analyses ${ }^{2,3}$ and the total precipitation values. It was thought, in particular, that further evidence of a connexion between precipitation and such occurrences as may induce changes and activation ${ }^{4}$ in aerosols could be obtained in this way. Since about half the stations selected by Reitan for his work coincide with points which were used by Junge, there appeared to be a good possibility of gaining further insight into natural nucleation phenomena.

If the precipitable water vapour $\pi$ is taken as a potential measure of the water stored in the atmosphere, and other parameters are maintained constant, an increment of precipitation $R$ with increase of $\pi$ will depend on an effective value of $\pi$ itself, and therefore on the difference:

$$
\alpha \pi-\beta R
$$

$\alpha$ and $\beta$ are constant for the purpose of this article (see later); more generally $\alpha$ is a number which depends on temperature, while $\beta$ has the dimensions of time.

Therefore:

$$
\frac{\mathrm{d} R}{\mathrm{~d} \pi}=K(\alpha \pi-\beta R)
$$

where $K$ is a constant.
When $\pi=0, R=0$; equation (1) integrates to:

$$
R=\frac{\alpha}{\beta}\left\{\pi-\frac{1}{K \beta}[1-\exp (-K \beta \pi)]\right\}
$$

The derivative of $(l a)$ with respect to $\pi$ can also be written :

$$
\frac{\mathrm{d} R}{\mathrm{~d} \pi}=\frac{\alpha}{\beta}\{1-\exp (-K \beta \pi)\}
$$

Thus, it is significant that for very high precipitable water vapour contents of the atmosphere (1b) approaches $\alpha / \beta$, while it is near to zero for very small values of $\pi$.

Clearly, the 'tendency of $\pi$ to precipitate' will depend considerably on temperature. If, however, differences in vertical temperature gradients from station to station are assumed to be such as not to have much influence on the data at hand, it becomes readily possible to correct $\pi$ for these effects. Rather than make corrections on the basis of the $\pi-T$ empirical relationship and the 'potential temperature' formula, we used an empirical latitude correction. A plot of $\pi$ against geographical latitude for lower stations (Fig. 1) gives an approximately straight-line relationship, on the basis of which Reitan's data of precipitable water vapour were all reduced to a latitude of $35^{\circ} \mathrm{N}$. by means of multiplication by the corresponding values of $\left(\pi_{35^{\circ}}\right):\left(\pi_{\text {lat. }}\right)$ which were obtained from the straight line derived by the method of least squares. This procedure results in a plot given in Fig. 2, where the corrected points are seen to fall into a type of pattern which might be expected, to be in agreement with equation $(1 a)$. 